ALMEIDA, Bruno Rotta; SALLET, Bruna Hoisler. Realidades prisionais e vulnerabilização étnica: aspectos sobre a questão indígena no sistema penitenciário brasileiro. Revista Eletrônica Direito e Política, Programa de Pós-Graduação Stricto Sensu em Ciência Jurídica da UNIVALI, Itajaí, v.13, n.3, 30 quadrimestre de 2018. Disponível em: www.univali.br/direitoepolitica - ISSN 1980-7791

\title{
REALIDADES PRISIONAIS E VULNERABILIZAÇÃO ÉTNICA: ASPECTOS SOBRE A QUESTÃO INDÍGENA NO SISTEMA PENITENCIÁRIO BRASILEIRO
}

\author{
PRISON REALITIES AND ETHNIC VULNERABILITY: ASPECTS ABOUT THE \\ INDIGENOUS ISSUE IN THE BRAZILIAN PRISON SYSTEM
}

\author{
Bruno Rotta Almeida ${ }^{1}$ \\ Bruna Hoisler Sallet ${ }^{2}$
}

SUMÁRIO: Introdução; 1 Sistema prisional e vulnerabilidades; 2 Violência institucional e desumanidade: o espaço das violações; 3 Questão indígena e sistema penal e penitenciário: a trajetória dos direitos e das políticas públicas; 4 Enfrentamentos e novas perspectivas a partir das realidades prisionais; Considerações finais; Referências das fontes citadas.

\section{RESUMO}

O artigo estuda a questão indígena no âmbito do sistema penitenciário brasileiro a partir da compreensão das realidades prisionais e do respeito ao multiculturalismo e pluralismo étnico. O texto procura indagar, por meio da consulta a informações penitenciárias e relatórios de distintos órgãos públicos, em que medida pode ser visualizada uma vulnerabilização étnica que afeta as pessoas indígenas privadas de liberdade no Brasil, a fim de propor, ao final, perspectivas de enfrentamentos ao problema em questão. A pesquisa possui relevância diante da necessária análise das sobrecargas carcerárias e da constante violações de direitos fundamentais nas unidades penais do país, notadamente com relação aos grupos sociais vulneráveis/vulnerabilizados. Para tanto, em um primeiro momento, o

\footnotetext{
1 Pós-Doutorando pela Universitat de Barcelona. Doutor e Mestre em Ciências Criminais pela PUCRS. Professor da Faculdade de Direito e do Mestrado em Direito da Universidade Federal de Pelotas, Rio Grande do Sul, Brasil. Coordenador do LIBERTAS - Programa de Enfrentamento da Vulnerabilidade em Ambientes Prisionais e do GEPUCS - Grupo de Estudos e Pesquisa em Punição e Controle Social. Membro da Red Cono Sur de Investigación en Cuestión Penitenciaria. Endereço de e-mail: bruno.ralm@yahoo.com.br

2 Graduanda em Direito pela Universidade Federal de Pelotas, com mobilidade acadêmica internacional na Faculdade de Direito da Universidade de Coimbra. Foi Bolsista de Iniciação Científica da Fundação de Amparo à Pesquisa do Estado do Rio Grande do Sul e da Universidade Federal de Pelotas, Rio Grande do Sul, Brasil. Pesquisadora do LIBERTAS e participante do GEPUCS - Grupo de Estudos e Pesquisa em Punição e Controle Social. Endereço de e-mail: bhsallet@gmail.com
} 
ALMEIDA, Bruno Rotta; SALLET, Bruna Hoisler. Realidades prisionais e vulnerabilização étnica: aspectos sobre a questão indígena no sistema penitenciário brasileiro. Revista Eletrônica Direito e Política, Programa de Pós-Graduação Stricto Sensu em Ciência Jurídica da UNIVALI, Itajaí, v.13, n.3, 30 quadrimestre de 2018. Disponível em: www.univali.br/direitoepolitica - ISSN 1980-7791

artigo expõe informações sobre a vulnerabilidade em âmbito prisional no país. A seguir, demonstra os caracteres que envolve a violência institucional e o desrespeito a direitos fundamentais nas prisões, indicando o espaço de violações dos direitos das pessoas indígenas privadas de liberdade. Após, exibe um repertório de normativas internacionais e nacionais sobre a trajetória dos direitos e das políticas públicas em torno da questão indígena. Por fim, oferece alguns enfrentamentos e novas perspectivas acerca do problema proposto.

Palavras-chave: Prisão; Vulnerabilidade; Etnia; Questão indígena; Brasil

\section{Abstract}

The paper studies the indigenous issue in the Brazilian prison system through prison realities and respect for multiculturalism and ethnic pluralism. After consulting penitentiary information and reports from different public agencies, the text explores the extent to which ethnic vulnerability of indigenous persons deprived of their liberty can be observed in Brazil. It proposes, in the end, prospects of confronting the problem in question. The research has relevance in the necessary analysis of prison overloads and constant violations of fundamental rights in the country's criminal units, especially on vulnerable social groups. To do so, at first, the paper exposes information about the vulnerability in prisons in the country. It then demonstrates the characteristics of institutional violence and disrespect for fundamental rights in prisons, indicating the scope of violations of the rights of indigenous persons deprived of their liberty. Afterwards, it presents a repertoire of international and national regulations on the trajectory of rights and public policies about the indigenous issue. Finally, it offers some confrontations and new perspectives about the proposed theme.

Keywords: Prison; Vulnerability; Ethnicity; Indigenous issue; Brazil

\section{INTRODUÇÃO}

Grandes contingentes de populações indígenas têm vivenciado acelerada e dinâmica transformação social. Questões possessórias, ambientais, de uso de drogas, aliciamento, entre outros, são as que comumente atiram os indígenas para dentro do ordenamento jurídico-penal brasileiro. Ocorre que, ao adentrar nesse sistema, pautado pela lógica eurocêntrica, não diferente da sociedade dominante que o rodeia, o indígena mais do que nunca necessita buscar alternativas para a sua sobrevivência física e cultural. 
ALMEIDA, Bruno Rotta; SALLET, Bruna Hoisler. Realidades prisionais e vulnerabilização étnica: aspectos sobre a questão indígena no sistema penitenciário brasileiro. Revista Eletrônica Direito e Política, Programa de Pós-Graduação Stricto Sensu em Ciência Jurídica da UNIVALI, Itajaí, v.13, n.3, 30 quadrimestre de 2018. Disponível em: www.univali.br/direitoepolitica - ISSN 1980-7791

Nesse sentido, é cogente a necessidade de rompimento da lógica de subalternização e vulnerabilização do indígena no direito brasileiro, o que pode ser proporcionado por novas perspectivas, tais como a dos estudos culturais. A vulnerabilização étnica alcança o sistema penal e penitenciário, e as violações decorrentes das desumanidades atingem a dignidade humana e a agenda de políticas de assistência e de respeito a direitos.

É relevante advertir a existência de uma variada normatização (nacional e internacional) de proteção a direitos e garantias fundamentais das pessoas privadas de liberdade. Junto a isso, os direitos indígenas foram reformulados, passando a se reconhecer a multiculturalidade e o respeito à singularidade desses grupos étnicos. Todavia, a conjuntura do sistema penal e penitenciário brasileiro se afasta, em certa medida, do estabelecido pelas normativas nacionais e internacionais. A atual conjuntura se apresenta ainda mais degradante à pessoa indígena, afetando práticas e tradições próprias e desrespeitando a própria diversidade.

Diante do exposto, faz-se necessário colocar em evidência novas perspectivas que buscam dar voz aos silenciados grupos sociais, notadamente os indígenas. A cultura de resistência deve ser apresentada por meio do respeito às diversidades. A questão étnica em âmbito penal e prisional perpassa especialmente pela adoção de estratégias de luta e de possibilidade de um novo direito e de uma nova prática jurídica. Este artigo visa, portanto, apresentar as sobrecargas prisionais no contexto brasileiro e a persistente desumanidade operada nas prisões do país, de modo a indicar perspectivas de enfrentamentos a partir da compreensão das realidades e do respeito às diferenças culturais em torno da questão indígena.

\section{SISTEMA PRISIONAL E VULNERABILIDADES}

O espaço carcerário - e toda a carga punitiva que carrega - constitui-se em um cenário de sistemáticas e cotidianas vitimizações. Não é difícil encontrar 
ALMEIDA, Bruno Rotta; SALLET, Bruna Hoisler. Realidades prisionais e vulnerabilização étnica: aspectos sobre a questão indígena no sistema penitenciário brasileiro. Revista Eletrônica Direito e Política, Programa de Pós-Graduação Stricto Sensu em Ciência Jurídica da UNIVALI, Itajaí, v.13, n.3, 30 quadrimestre de 2018. Disponível em: www.univali.br/direitoepolitica - ISSN 1980-7791

o nível de seletividade penal nas prisões, lugar onde a população se enquadra numa massa com determinados e evidentes marcadores ${ }^{3}$.

Os modos de segregação e estigmatização penal fazem com que a prisão signifique uma exclusão, e não somente uma imobilização. A prisão proporciona uma duradoura e talvez inalterável exclusão-sofrimento, e a identificação do crime com os desclassificados, ou a "criminalização da pobreza", nas palavras de Zygmunt Bauman ${ }^{4}$. Segundo Loïc Wacquant ${ }^{5}$, o encarceramento é um tipo de componente da política de contenção repressiva dos pobres. Para o público em geral, os delinquentes mais comuns são oriundos dos guetos/favelas urbanos, sendo considerados como áreas produtoras de crime e criminosos. Os crimes e os criminosos são determinados e apontados pela sociedade e por meio da própria gestão política de exclusão social.

A prisão, para David Garland ${ }^{6}$, é concebida, hoje, de modo explícito, como mecanismo de exclusão e controle. O cárcere é usado como uma espécie de reservatório, na qual as pessoas supostamente perigosas são segregadas/isolados em nome da segurança pública. Os delitos e os delinquentes são determinados e apontados pela sociedade e por meio da própria gestão de segurança pública, que invade bairros à procura de pequenos e infelizes perdedores do jogo.

Para Luigi Ferrajoli, cada conquista de direitos, e cada progresso na igualdade e nas garantias da pessoa, tem sido determinada pela

3 NEUMAN, Elías. Victimologia y Control Social: las victimas del sistema penal. Buenos Aires: Universidad, 1994, p. 16.

4 BAUMAN, Zygmunt. Globalização: as consequências humanas. Rio de Janeiro: Jorge Zahar, 1999, p. 134.

5 WACQUANT, Loïc. Punir os pobres: a nova gestão da miséria nos Estados Unidos. Rio de Janeiro: Instituto Carioca de Criminologia, F. Bastos, 2001, p. 28.

6 GARLAND, David. A cultura do controle: crime e ordem social na sociedade contemporânea. Rio de Janeiro: Revan, 2008, p. 380.

7 FERRAJOLI, Luigi. Filosofía del mal y garantismo. In: CUÉLLAR, Alejandro Forero; RIVERA BEIRAS, Iñaki; GORSKI, Hector C. Silveira. (ed.). Filosofía del mal y memoria. Anthropos Editorial; Observatori del Sistema Penal i els Drets Humans; Universitat de Barcelona: Barcelona, 2012, p. 107. 
ALMEIDA, Bruno Rotta; SALLET, Bruna Hoisler. Realidades prisionais e vulnerabilização étnica: aspectos sobre a questão indígena no sistema penitenciário brasileiro. Revista Eletrônica Direito e Política, Programa de Pós-Graduação Stricto Sensu em Ciência Jurídica da UNIVALI, Itajaí, v.13, n.3, 30 quadrimestre de 2018. Disponível em: www.univali.br/direitoepolitica - ISSN 1980-7791

manifestação de um mal discriminatório e racista. Hoje em dia, o grande desafio da democracia é aquele gerado pela desigualdade agravada pelo fator de desqualificação racista dos excluídos, selecionados como inferiores e por isso destinados à exclusão.

A vulnerabilidade dos grupos sociais no âmbito prisional se constata nas informações referentes ao perfil da população privada de liberdade. Observa-se uma gramática de violência institucional ainda mais intensa quando envolve grupos sociais vulneráveis (LGBT, deficiência, situação de rua, indígenas, estrangeiros, autores de crimes sexuais, crianças e adolescentes, saúde mental e uso de drogas, pessoas idosas, população negra, jovens, mulheres).

A partir da análise da amostra de pessoas privadas, pode-se afirmar que $55 \%$ da população prisional é formada por jovens (até 29 anos), sendo que a mesma população representa $18 \%$ da população total no Brasil. O grau de escolaridade é extremamente baixo. Aproximadamente oito em cada dez pessoas presas estudaram, no máximo, até o ensino fundamental, enquanto a média nacional de pessoas que não frequentaram o ensino fundamental ou o têm incompleto é de $61 \%{ }^{8}$.

A distribuição da população privada de liberdade por cor ou etnia evidencia a sobrerrepresentação de pessoas negras presas: dois em cada três presos são negros. A porcentagem de pessoas negras no sistema prisional é de 64\%, sendo que, na população brasileira em geral, a proporção é significativamente menor $(53 \%)^{9}$.

A população prisional feminina atingiu a marca de 42 mil mulheres privadas de liberdade, o que representa um aumento de $656 \%$ em relação ao total

8 BRASIL. Ministério da Justiça. Departamento Penitenciário Nacional. Levantamento Nacional de Informações Penitenciárias Infopen - junho de 2016. Disponível em: http://www.justica.gov.br/ Acesso em: 25 fev. 2018.

9 BRASIL. Ministério da Justiça. Departamento Penitenciário Nacional. Levantamento Nacional de Informações Penitenciárias Infopen - junho de 2016. Disponível em: http://www.justica.gov.br/ Acesso em: 25 fev. 2018. 
ALMEIDA, Bruno Rotta; SALLET, Bruna Hoisler. Realidades prisionais e vulnerabilização étnica: aspectos sobre a questão indígena no sistema penitenciário brasileiro. Revista Eletrônica Direito e Política, Programa de Pós-Graduação Stricto Sensu em Ciência Jurídica da UNIVALI, Itajaí, v.13, n.3, 30 quadrimestre de 2018. Disponível em: www.univali.br/direitoepolitica - ISSN 1980-7791

registrado no início dos anos 2000, quando menos de 6 mil mulheres se encontravam no sistema prisional. No mesmo período, a população prisional masculina cresceu 293\%. Entre 2000 e 2016, a taxa de encarceramento de mulheres aumentou em 525\%, passando de 6,5 mulheres encarceradas para cada grupo de 100 mil mulheres em 2000 para 40,6 mulheres encarceradas em 100 mil. Do total de 42 mil mulheres privadas de liberdade, $45 \%$ não haviam sido ainda julgadas e condenadas $^{10}$.

Uma informação que reforça a sobrecarga prisional feminina é a natureza dos estabelecimentos penais. A maior parte dos estabelecimentos foi projetada para o público masculino: $74 \%$ das unidades prisionais destinamse aos homens, $7 \%$ ao público feminino e outros $16 \%$ são caracterizados como mistos, o que significa que podem contar com alas ou celas específicas para o aprisionamento de mulheres dentro de um estabelecimento originalmente masculino ${ }^{11}$. Em geral, as unidades prisionais são incapazes de observar as especificidades de espaços e serviços destinados às mulheres.

Acerca do encarceramento de indígenas, o censo Infopen de junho de 2014 apresentou um percentual de $0,2 \%$ de indígenas no sistema prisional do país. Em dezembro desse mesmo ano, o índice chegou a 0,13\%. Nota-se uma sobrerrepresentação de indígenas privados de liberdade em diversos estados do país: Alagoas ( $0,37 \%$ nas prisões; $0,23 \%$ na população em geral); Ceará $(0,68 \%$ nas prisões; $0,21 \%$ na população em geral); Mato Grosso do Sul (1,28\% nas prisões; $0,82 \%$ na população em geral); Pernambuco $(0,94 \%$ nas prisões; $0,62 \%$ na população em geral); Piauí $(0,40 \%$ nas prisões; $0,14 \%$ na população em geral); Rondônia ( $0,40 \%$ nas

10 BRASIL. Ministério da Justiça. Departamento Penitenciário Nacional. Levantamento Nacional de Informações Penitenciárias Infopen - junho de 2016. Disponível em: http://www.justica.gov.br/ Acesso em: 25 fev. 2018.

11 BRASIL. Ministério da Justiça. Departamento Penitenciário Nacional. Levantamento Nacional de Informações Penitenciárias Infopen - junho de 2016. Disponível em: http://www.justica.gov.br/ Acesso em: 25 fev. 2018. 
ALMEIDA, Bruno Rotta; SALLET, Bruna Hoisler. Realidades prisionais e vulnerabilização étnica: aspectos sobre a questão indígena no sistema penitenciário brasileiro. Revista Eletrônica Direito e Política, Programa de Pós-Graduação Stricto Sensu em Ciência Jurídica da UNIVALI, Itajaí, v.13, n.3, 30 quadrimestre de 2018. Disponível em: www.univali.br/direitoepolitica - ISSN 1980-7791

prisões; $0,29 \%$ na população em geral); e Roraima (5,65\% nas prisões; $4,80 \%$ na população em geral $)^{12}$.

É importante mencionar que tais números não são precisos, pois a estimativa é subdimensionada pela "descaracterização étnica" e a consequente invisibilidade legal dos índios na esfera jurídica, corroborada por ausência de consolidado registro de dados étnicos no Infopen ${ }^{13}$.

A violência institucional em torno da vulnerabilidade no sistema prisional também pode ser verificada na disponibilidade de espaço adequado para os grupos sociais vulneráveis.

Sobre a destinação de lugar adequado para pessoas lésbicas, gays, bissexuais e transgêneros (LGBT): 10 (1\%) unidades informaram possuir ala específica; 73 (5\%) unidades registraram ter cela específica; 1.217 (86\%) informaram não possuir ala nem cela específicas; e 120 (8\%) unidades não apresentaram informação ${ }^{14}$.

Esses números não são tão diferentes dos prestados relativamente à destinação a pessoas idosas: 22 (2\%) estabelecimentos afirmaram possuir ala específica; 70 (5\%) informaram ter cela específica; em 1.208 (85\%) unidades, não há ala nem cela específicas; e 120 (8\%) unidades não prestaram informação ${ }^{15}$.

12 BRASIL. Ministério da Justiça. Departamento Penitenciário Nacional. Levantamento Nacional de Informações Penitenciárias Infopen - junho de 2014. Disponível em: http://www.justica.gov.br/. Acesso em: 20 jan. 2018; BRASIL. Ministério da Justiça. Departamento Penitenciário Nacional. Levantamento Nacional de Informações Penitenciárias Infopen - dezembro de 2014. Disponível em: http://www.justica.gov.br/. Acesso em: 20 jan. 2018.

13 ABA - ASSOCIAÇÃO BRASILEIRA DE ANTROPOLOGIA; PGR - PROCURADORIA GERAL DA REPÚBLICA. Criminalização e Situação Prisional de Índios no Brasil. Edital Projeto de Pesquisa ESMPU nº 19/2006. Relatório Final. Brasília: ABA, 2008.

14 BRASIL. Ministério da Justiça. Departamento Penitenciário Nacional. Levantamento Nacional de Informações Penitenciárias Infopen - junho de 2014. Disponível em: http://www.justica.gov.br/. Acesso em: 20 jan. 2018.

15 BRASIL. Ministério da Justiça. Departamento Penitenciário Nacional. Levantamento Nacional de Informações Penitenciárias Infopen - junho de 2014. Disponível em: http://www.justica.gov.br/. Acesso em: 20 jan. 2018. 
ALMEIDA, Bruno Rotta; SALLET, Bruna Hoisler. Realidades prisionais e vulnerabilização étnica: aspectos sobre a questão indígena no sistema penitenciário brasileiro. Revista Eletrônica Direito e Política, Programa de Pós-Graduação Stricto Sensu em Ciência Jurídica da UNIVALI, Itajaí, v.13, n.3, 30 quadrimestre de 2018. Disponível em: www.univali.br/direitoepolitica - ISSN 1980-7791

Relativamente à destinação dos estabelecimentos para estrangeiros, observou-se o seguinte: 1 (0\%) unidade informou possuir ala específica; 11 (1\%) unidades registraram ter cela específica; 1.289 (91\%) informaram não possuir ala nem cela específicas; e 119 (8\%) não apresentaram informação ${ }^{16}$.

A respeito dos estabelecimentos penais adaptados para a acessibilidade de pessoas com deficiência, em apenas 87 (6\%) unidades verificou-se a existência de módulos, alas ou celas acessíveis e adaptados para pessoas com deficiência, em conformidade com a legislação em vigor. Em 49 (4\%) estabelecimentos há módulos, alas ou celas adaptados, porém em desrespeito às normas técnicas e legais. Para mais de 82\% (1.164) das unidades prisionais não há qualquer adaptação e acessibilidade para pessoas em situação de deficiência. Ainda, 120 (8\%) unidades não forneceram dados ao censo ${ }^{17}$.

Sobre a destinação de espaço para indígenas, encontramos o que segue: 1 (0\%) estabelecimento afirmou possuir ala específica; 7 (1\%) informaram ter cela específica; em 1.293 (91\%) unidades, não há ala nem cela específicas; e 119 (9\%) unidades não prestaram informação ${ }^{18}$.

As violações que decorrem das desumanidades contra os grupos sociais vulneráveis, incluídos também os indígenas desde a sua peculiar dimensão, atingem a dignidade humana e a distribuição de políticas de assistência à saúde, jurídica, social, educacional, laboral etc., bem como o respeito à cultura e às individualidades de determinado grupo social.

16 BRASIL. Ministério da Justiça. Departamento Penitenciário Nacional. Levantamento Nacional de Informações Penitenciárias Infopen - junho de 2014. Disponível em: http://www.justica.gov.br/. Acesso em: 20 jan. 2018.

17 BRASIL. Ministério da Justiça. Departamento Penitenciário Nacional. Levantamento Nacional de Informações Penitenciárias Infopen - junho de 2014. Disponível em: http://www.justica.gov.br/. Acesso em: 20 jan. 2018.

18 BRASIL. Ministério da Justiça. Departamento Penitenciário Nacional. Levantamento Nacional de Informações Penitenciárias Infopen - junho de 2014. Disponível em: http://www.justica.gov.br/. Acesso em: 20 jan. 2018. 
ALMEIDA, Bruno Rotta; SALLET, Bruna Hoisler. Realidades prisionais e vulnerabilização étnica: aspectos sobre a questão indígena no sistema penitenciário brasileiro. Revista Eletrônica Direito e Política, Programa de Pós-Graduação Stricto Sensu em Ciência Jurídica da UNIVALI, Itajaí, v.13, n.3, 30 quadrimestre de 2018. Disponível em: www.univali.br/direitoepolitica - ISSN 1980-7791

\section{VIOLÊNCIA INSTITUCIONAL E DESUMANIDADE: O ESPAÇO DAS VIOLAÇÕES}

A luta pelos direitos dos presos alcançou o século $X X$, com o nascimento de instrumentos normativos internacionais de garantia e proteção dos direitos humanos. Toda uma gama de normativas internacionais foi promulgada visando seguir um bem-estar punitivo e de respeito aos direitos e garantias das pessoas privadas de liberdades.

No contexto da Organização das Nações Unidas, destacamos: Declaração Universal dos Direitos Humanos (1948); Regras Mínimas para o Tratamento de Reclusos (1955); Pacto Internacional de Direitos Civis e Políticos (1966); Convenção contra a tortura e outro tratamentos ou penas cruéis, desumanos ou degradantes (1984); Conjunto de Princípios para a Proteção de todas as Pessoas submetidas a qualquer forma de Detenção ou Prisão (1988); Protocolo Facultativo à Convenção contra a Tortura e Outros Tratamentos ou Penas Cruéis, Desumanos ou Degradantes (2002); Nelson Mandela Rules (2015). No panorama americano, localizamos: Declaração Americana de Direitos e Deveres do Homem (1948); Convenção Americana de Direitos Humanos (1969); e a Convenção Interamericana para Prevenir e Punir a Tortura (1985).

No ordenamento jurídico brasileiro, a dignidade da pessoa humana toma posição destacada no art. $1^{0}$ da Constituição de 1988 . O princípio da humanidade funciona como elemento de contenção do poder punitivo na execução da pena, a partir da proibição da tortura e do tratamento cruel e degradante (art. 50, III), da individualização da pena (art. 50, III), da proibição das penas de morte, cruéis ou perpétuas (art. 50, XLVII), do cumprimento da pena em estabelecimento apropriado, de acordo com a natureza do delito, a idade e o sexo do apenado (art. 50, XLVIII) e do respeito à integridade física e moral das pessoas privadas da liberdade 0 (art. 50, XLIX). 
ALMEIDA, Bruno Rotta; SALLET, Bruna Hoisler. Realidades prisionais e vulnerabilização étnica: aspectos sobre a questão indígena no sistema penitenciário brasileiro. Revista Eletrônica Direito e Política, Programa de Pós-Graduação Stricto Sensu em Ciência Jurídica da UNIVALI, Itajaí, v.13, n.3, 30 quadrimestre de 2018. Disponível em: www.univali.br/direitoepolitica - ISSN 1980-7791

A Lei de Execução Penal (Lei n. 7.210/1984) prevê uma série de medidas assistenciais - obrigações estatais - de prestar à pessoa privada da liberdade a assistência material, à saúde, jurídica, educacional, social, religiosa, orientação para a reintegração à sociedade etc. A mesma lei enaltece no art. 40 o respeito à integridade física e moral dos condenados e dos presos provisórios por parte de todas as autoridades.

Há, portanto, uma variada normatização, em âmbito internacional e nacional, de direitos e garantias protetores dos direitos fundamentais das pessoas privadas da liberdade. A máxima da humanidade proíbe, na execução da pena, a imposição ou consolidação de determinados padrões e medidas irracionais e atentatórios aos direitos fundamentais.

Atualmente testemunha-se uma aceleração da punição por meio do encarceramento. A utilização de um controle penal incisivo e altamente punitivo chama a atenção pelo impacto das heranças colonizadoras, autoritárias e repressivas nas dinâmicas penitenciárias atuais. O discurso humanizado da prisão é abandonado por uma política criminal cada vez mais arbitrária e intensificadora de desigualdades e desumanidades.

No primeiro semestre de 2016, o número de pessoas privadas de liberdade no Brasil ultrapassou a marca dos 700 mil, mais de 8 vezes maior do que em 1990. Entre 2000 e 2016, a taxa de aprisionamento aumentou em 157\% no Brasil. Em 2000 existiam 137 pessoas presas para cada grupo de 100 mil habitantes. Em junho de 2016, eram 352,6 pessoas presas para cada 100 mil habitantes. Em relação ao número de vagas, observamos um déficit total de 358.663 mil vagas e uma taxa de ocupação média de $197,4 \%$ em todo o país, cenário constantemente agravado ano após ano ${ }^{19}$.

De acordo com o levantamento realizado em junho de 2016, 40\% das pessoas presas no Brasil não haviam sido ainda julgadas e condenadas. Os

19 BRASIL. Ministério da Justiça. Departamento Penitenciário Nacional. Levantamento Nacional de Informações Penitenciárias Infopen - junho de 2016. Disponível em: http://www.justica.gov.br/ Acesso em: 25 fev. 2018. 
ALMEIDA, Bruno Rotta; SALLET, Bruna Hoisler. Realidades prisionais e vulnerabilização étnica: aspectos sobre a questão indígena no sistema penitenciário brasileiro. Revista Eletrônica Direito e Política, Programa de Pós-Graduação Stricto Sensu em Ciência Jurídica da UNIVALI, Itajaí, v.13, n.3, 30 quadrimestre de 2018. Disponível em: www.univali.br/direitoepolitica - ISSN 1980-7791

crimes de tráfico de drogas correspondem a $28 \%$ das incidências penais. Os crimes de roubo e furto somam $37 \%$ das incidências e os homicídios representam $11 \%{ }^{20}$.

Os últimos meses de 2016 e os primeiros meses de 2017 registraram mortes e massacres dentro de unidades prisionais em distintos estados brasileiros. Em 2014, a taxa de óbitos por homicídio nas unidades prisionais do Brasil era de 9,52 para cada 10 mil pessoas privadas de liberdade, quase seis vezes maior do que a taxa de crimes letais intencionais verificada no Brasil no mesmo ano. A taxa de suicídio era de 3,24 para cada 10 mil pessoas presas. De 2014 a 2016, verifica-se uma diminuição no quantitativo de mortes sob custódia no país, porém, as taxas permanecem altas (13,6 mortes para cada 10 mil pessoas presas $)^{21}$.

Alguns presídios vêm registrando, nos últimos anos, ocorrências de tortura e violação à integridade física e corporal das pessoas presas. O Presídio Urso Branco, em Rondônia, é supervisionado pela Organização dos Estados Americanos - OEA desde 2002, quando foi palco de um massacre de presos. O Complexo de Curado foi objeto de notificação da Comissão Interamericana de Direitos Humanos da OEA devido a diversos abusos. No Presídio Central de Porto Alegre há registro de tortura, deficiências sanitárias e outras situação degradantes, sendo objeto de resolução da Comissão Interamericana de Direitos Humanos da OEA. O Complexo de Pedrinhas tem sido testemunha de assassinatos, decapitações, torturas e abusos sexuais, e também foi objeto de notificação pela OEA.

20 BRASIL. Ministério da Justiça. Departamento Penitenciário Nacional. Levantamento Nacional de Informações Penitenciárias Infopen - junho de 2016. Disponível em: http://www.justica.gov.br/ Acesso em: 25 fev. 2018

21 BRASIL. Ministério da Justiça. Departamento Penitenciário Nacional. Levantamento Nacional de Informações Penitenciárias Infopen - junho de 2014. Disponível em: http://www.justica.gov.br/. Acesso em: 20 jan. 2018; e BRASIL. Ministério da Justiça. Departamento Penitenciário Nacional. Levantamento Nacional de Informações Penitenciárias Infopen - junho de 2016. Disponível em: http://www.justica.gov.br/ Acesso em: 25 fev. 2018. 
ALMEIDA, Bruno Rotta; SALLET, Bruna Hoisler. Realidades prisionais e vulnerabilização étnica: aspectos sobre a questão indígena no sistema penitenciário brasileiro. Revista Eletrônica Direito e Política, Programa de Pós-Graduação Stricto Sensu em Ciência Jurídica da UNIVALI, Itajaí, v.13, n.3, 30 quadrimestre de 2018. Disponível em: www.univali.br/direitoepolitica - ISSN 1980-7791

Outra imagem cruel diz respeito à incidência de enfermidades. A cada 100 pessoas presas em dezembro de 2014, 1,3 viviam com HIV. Da mesma forma, $0,5 \%$ da população prisional vivia com sífilis, 0,6\% com hepatite, $0,9 \%$ com tuberculose e $0,5 \%$ com outras doenças. Os dados do Portal da Saúde apontam que as pessoas privadas de liberdade têm, em média, uma chance 28 vezes maior do que a população em geral de contrair tuberculose ${ }^{22}$. Tudo isso se aproxima ao que Elías Neuman ${ }^{23}$ chamou de prisão-morte.

A violência institucional sofrida por indígenas privados de liberdade também se verifica na ausência de representação adequada para acompanhar os respectivos processos criminais. O relatório do mutirão carcerário do Conselho Nacional de Justiça, realizado no estado de Mato Grosso do Sul, em 2011, registrou denúncias sobre cerca de 130 indígenas que estavam presos em diversas unidades prisionais inexistindo qualquer representante para acompanhar os processos e assistir os indígenas ${ }^{24}$.

No relatório do Mecanismo Nacional de Prevenção e Combate à Tortura de 2016/201725, apontam-se diversas problemáticas de violências enfrentadas nas penitenciárias brasileiras e, especificamente sobre os indígenas, há denúncia sobre a situação da Penitenciária Estadual de Dourados/MS, prescrevendo a necessidade de garantias diferenciadas de devido processo para acusados indígenas, como intérpretes para seu idioma, perícia

22 BRASIL. Ministério da Justiça. Departamento Penitenciário Nacional. Levantamento Nacional de Informações Penitenciárias Infopen - dezembro de 2014. Disponível em: http://www.justica.gov.br/. Acesso em: 20 jan. 2018; e BRASIL. Ministério da Saúde, Portal Saúde. Disponível em http://portalsaude.saude.gov.br/index.php/o-ministerio/principal/leiamais-o-ministerio/743-secretariasvs/vigilancia-de-a-a-z/tuberculose/I2-tuberculose/11941viajantes-tuberculose. Acesso em: 25 fev. 2018.

23 NEUMAN, Elías. El estado penal y la prisión-muerte. Buenos Aires: Editorial Universidad, 2001.

${ }^{24}$ BRASIL. Conselho Nacional de Justiça. Mutirão Carcerário do Estado de Mato Grosso do Sul - Relatório Geral. $2011 . \quad$ Disponível em: http://www.cnj.jus.br/images/programas/mutirao-

carcerario/relatorios/relatorio_final_mato_grosso_do_sul.pdf Acesso em 27 mai. 2018.

25 BRASIL. Mecanismo Nacional de Prevenção e Combate à Tortura. Relatório Anual 2016-2017. Disponível em: http://pfdc.pgr.mpf.mp.br/temas-de-atuacao/tortura/relatoriosmnpc/relatorio-anual-2016-2017 Acesso em 27 mai. 2018. 
ALMEIDA, Bruno Rotta; SALLET, Bruna Hoisler. Realidades prisionais e vulnerabilização étnica: aspectos sobre a questão indígena no sistema penitenciário brasileiro. Revista Eletrônica Direito e Política, Programa de Pós-Graduação Stricto Sensu em Ciência Jurídica da UNIVALI, Itajaí, v.13, n.3, 30 quadrimestre de 2018. Disponível em: www.univali.br/direitoepolitica - ISSN 1980-7791

antropológica e participação da FUNAI, bem como a necessidade de agentes públicos que falem os idiomas indígenas.

Essas violências podem ser demonstradas pela gênese contraditória do cárcere no Brasil, bem como nas continuidades de métodos e práticas, e diante da formação de uma conduta omissa do Estado com relação aos cidadãos. Esses comportamentos, reforçados muitas vezes por tendências colonizadoras e autoritárias, legitimam o sofrimento por meio da punição. A situação enfrentada pelos povos indígenas está longe de uma concepção de respeito à dignidade.

\section{QUESTÃo INDÍgenA e Sistema PENAL e PENITENCIÁRIO: A TRAJETÓRIA DOS DIREITOS E DAS POLÍTICAS PÚBLICAS}

Debates dos séculos XV e XVI questionavam se os índios tinham alma e, nesse contexto, o Papa Paulo III determinou que a alma dos povos selvagens seria como um receptáculo vazio, uma anima nullius, muito semelhante à terra nullius, o conceito de vazio jurídico que justificou a apropriação e violência sobre o 'outro lado da linha'26. Somente a partir do século XX as situações as quais esses povos vivenciavam passaram a ser debatidas internacionalmente e de forma consideravelmente sólida.

A questão indígena apareceu primeiramente na Organização Internacional do Trabalho (OIT), órgão especializado da Organização das Nações Unidas (ONU), quando da discussão acerca do trabalho escravo o qual este povo era comumente submetido, e não propriamente devido a sua condição de indígena. A partir disso, a OIT tornou-se importante instrumento de debate

\footnotetext{
26 Do outro lado não há conhecimento real; existem crenças, opiniões, magia, idolatria, entendimentos intuitivos ou subjetivos, que na melhor das hipóteses podem se tornar objeto ou matéria-prima de investigações científicas. Assim, a linha visível que separa a ciência de seus "outros" modernos está assente na linha abissal invisível que separa, de um lado, ciência, filosofia e teologia e, de outro, conhecimentos tornados incomensuráveis e incompreensíveis por não obedecerem nem aos critérios científicos de verdade nem aos critérios dos conhecimentos reconhecidos como alternativos, da filosofia e da teologia (SANTOS, Boaventura de Sousa. Para além do pensamento abissal: das linhas globais a uma ecologia de saberes. 2007. Disponível em: http://dx.doi.org/10.1590/S010133002007000300004 Acesso em 27 mai. 2018.)
} 
ALMEIDA, Bruno Rotta; SALLET, Bruna Hoisler. Realidades prisionais e vulnerabilização étnica: aspectos sobre a questão indígena no sistema penitenciário brasileiro. Revista Eletrônica Direito e Política, Programa de Pós-Graduação Stricto Sensu em Ciência Jurídica da UNIVALI, Itajaí, v.13, n.3, 30 quadrimestre de 2018. Disponível em: www.univali.br/direitoepolitica - ISSN 1980-7791

sobre os direitos indígenas e, posteriormente, a organização verificou a necessidade de uma nova abordagem que renegasse a visão integracionista e adotasse uma perspectiva de respeito à autonomia e à diversidade indígena.

Dessa forma, em 1989, foi aprovada a Convenção no 169 da OIT sobre Povos Indígenas e Tribais em Países Independentes, sob uma nova orientação, abandonando, portanto, a noção de integração do indígena a uma suposta comunhão nacional. No texto preambular são reconhecidas "as aspirações desses povos a assumir o controle de suas próprias instituições e formas de vida e seu desenvolvimento econômico, e manter e fortalecer suas identidades, línguas e religiões, dentro do âmbito dos Estados onde moram"27 (ONU/OIT, 1989). O Brasil ratificou a Convenção, tornando-se obrigatório o cumprimento de suas disposições.

O artigo 90, da Convenção no 169, observa que, de forma compatível com o sistema jurídico nacional e com os direitos humanos, deveriam ser respeitados os métodos tradicionais utilizados pelos povos indígenas para repressão de delitos cometidos por seus membros, bem como deveriam ser levados em conta os costumes desses povos quando tribunais forem solicitados a pronunciarem-se acerca de questões.

O artigo 10, por sua vez, dispõe sobre a aplicação de legislação geral aos indígenas, referindo que, ao sancioná-los penalmente, deverão ser observadas suas características próprias, além de garantir a preferência a outros métodos de punição que não o encarceramento, conforme indica-se:

Artigo 10

1. Quando sanções penais sejam impostas pela legislação geral a membros dos povos mencionados, deverão ser levadas em conta as suas características econômicas, sociais e culturais.

27 ONU. OIT. Convenção 169 sobre povos indígenas e tribais. 1989. Disponível em: http://www.ilo.org/brasilia/convencoes/WCMS_236247/lang--pt/index.htm Acesso em 27 mai. 2018. 
ALMEIDA, Bruno Rotta; SALLET, Bruna Hoisler. Realidades prisionais e vulnerabilização étnica: aspectos sobre a questão indígena no sistema penitenciário brasileiro. Revista Eletrônica Direito e Política, Programa de Pós-Graduação Stricto Sensu em Ciência Jurídica da UNIVALI, Itajaí, v.13, n.3, 30 quadrimestre de 2018. Disponível em: www.univali.br/direitoepolitica - ISSN 1980-7791

2. Dever-se-á dar preferência a tipos de punição outros que o encarceramento. ${ }^{28}$

A partir do arcabouço jurídico proporcionado pela OIT, a Assembleia Geral das Nações Unidas aprovou, em 2007, a Declaração das Nações Unidas sobre os Direitos dos Povos Indígenas reconhecendo e reafirmando que os indivíduos indígenas têm direito a todos os direitos humanos reconhecidos no direito internacional. A respeito da determinação de suas instituições, procedimentos, costumes ou sistemas jurídicos, foi disposto que os povos indígenas têm o direito de promovê-los, assim como de determinar a responsabilidade dos indivíduos para com suas comunidades. Nesse sentido, colaciona-se os seguintes artigos:

\section{Artigo 33}

1. Os povos indígenas têm o direito de determinar sua própria identidade ou composição conforme seus costumes e tradições. Isso não prejudica o direito dos indígenas de obterem a cidadania dos Estados onde vivem.

2. Os povos indígenas têm o direito de determinar as estruturas e de eleger a composição de suas instituições em conformidade com seus próprios procedimentos.

\section{Artigo 34}

Os povos indígenas têm o direito de promover, desenvolver e manter suas estruturas institucionais e seus próprios costumes, espiritualidade, tradições, procedimentos, práticas e, quando existam, costumes ou sistema jurídicos, em conformidade com as normas internacionais de direitos humanos.

Artigo 35

Os povos indígenas têm o direito de determinar as responsabilidades dos indivíduos para com suas comunidades. ${ }^{29}$

28 ONU. OIT. Convenção 169 sobre povos indígenas e tribais. 1989. Disponível em: http://www.ilo.org/brasilia/convencoes/WCMS_236247/lang--pt/index.htm Acesso em 27 mai. 2018. 
ALMEIDA, Bruno Rotta; SALLET, Bruna Hoisler. Realidades prisionais e vulnerabilização étnica: aspectos sobre a questão indígena no sistema penitenciário brasileiro. Revista Eletrônica Direito e Política, Programa de Pós-Graduação Stricto Sensu em Ciência Jurídica da UNIVALI, Itajaí, v.13, n.3, 30 quadrimestre de 2018. Disponível em: www.univali.br/direitoepolitica - ISSN 1980-7791

Em seu turno, as Regras de Bangkok, aprovadas na Assembleia Geral das Nações Unidas, em 2010, constituem-se em diretrizes para o tratamento específico de mulheres presas e em medidas não privativas de liberdade para mulheres infratoras. No instrumento há um recorte voltado para as minorias e indígenas, representado pelas regras 54 e 55 . A primeira assim dispõe:

\section{Regra 54}

Autoridades prisionais deverão reconhecer que mulheres presas de diferentes tradições religiosas e culturais possuem necessidades distintas e podem enfrentar múltiplas formas de discriminação para obter acesso a programas e serviços cuja implementação seja ligada a fatores de gênero e culturais. Desta forma, autoridades prisionais deverão oferecer programas $e$ serviços abrangentes que incluam essas necessidades, em consulta com as próprias presas e os grupos pertinente. ${ }^{30}$

Dessa forma, portanto, há o reconhecimento de que complicações discriminatórias hão de ser vivenciadas pelas presas com condição étnica específica, devendo a administração penitenciária atentar-se às referidas questões. Depois, a Regra 55 indica a necessidade de revisão dos serviços de atenção, o que deverá ser feito em consulta com os grupos correspondentes, antes e após a soltura, para assegurar que sejam adequados e acessíveis às presas de origem indígena e de grupos étnicos e raciais minoritários,

Recentemente, em 2016, contribuindo para o fortalecimento específico dos direitos indígenas no continente americano, editou-se a Declaração Americana dos Povos Indígenas, a qual ineditamente adotou o critério da autoidentificação. Em relação ao paradigma assimilacionista/integracionista,

29 ONU. Declaração das Nações Unidas sobre os Direitos dos Povos Indígenas. 2008. Disponível em: http://www.un.org/esa/socdev/unpfii/documents/DRIPS_pt.pdf Acesso em 27 mai. 2018.

30 BRASIL. Conselho Nacional de Justiça. Regras de Bangkok: Regras das Nações Unidas para o Tratamento de Mulheres Presas e Medidas Não Privativas de Liberdade para Mulheres Infratoras. 1. Ed - Brasília: Conselho Nacional de Justiça, 2016. 
ALMEIDA, Bruno Rotta; SALLET, Bruna Hoisler. Realidades prisionais e vulnerabilização étnica: aspectos sobre a questão indígena no sistema penitenciário brasileiro. Revista Eletrônica Direito e Política, Programa de Pós-Graduação Stricto Sensu em Ciência Jurídica da UNIVALI, Itajaí, v.13, n.3, 30 quadrimestre de 2018. Disponível em: www.univali.br/direitoepolitica - ISSN 1980-7791

o qual já havia sido afastado pela inteligência da Convenção 169 da OIT, a Declaração Americana dos Povos Indígenas reforçou seu repúdio, de forma expressa, assim descrevendo em seu artigo 10:

Artigo X. Repúdio à assimilação 1 . Os povos indígenas têm o direito de manter, expressar e desenvolver livremente sua identidade cultural em todos os seus aspectos, livre de toda intenção externa de assimilação. 2. Os Estados não deverão desenvolver, adotar, apoiar ou favorecer política alguma de assimilação dos povos indígenas nem de destruição de suas culturas. ${ }^{31}$

Além disso, o documento assegurou que os povos indígenas possuem o direito a promoverem suas estruturas institucionais, sistemas jurídicos, procedimentos, entre outros, desde que em conformidade com os direitos humanos, devendo tais sistemas serem reconhecidos e respeitados pelo ordenamento jurídico nacional, conforme colaciona-se:

Artigo XXII. Direito e jurisdição indígena

1. Os povos indígenas têm direito a promover, desenvolver e manter suas estruturas institucionais e seus próprios costumes, espiritualidade, tradições, procedimentos, práticas e, quando existam, costumes ou sistemas jurídicos, em conformidade com as normas internacionais de direitos humanos.

2. O direito e os sistemas jurídicos indígenas serão reconhecidos e respeitados pela ordem jurídica nacional, regional e internacional ${ }^{32}$.

O item 3, do artigo 22, dispõe sobre como devem ser tratados os assuntos relacionados aos povos indígenas na jurisdição de cada Estado, regulando que deve ser promovida a plena representação, com dignidade e igualdade perante a lei. Para tanto, devem gozar de igual proteção e, inclusive, de uso de intérpretes linguísticos e culturais, nesse sentido:

31 OEA. Declaração Americana sobre os Direitos dos Povos Indígenas. Disponível em: https://www.oas.org/en/sare/documents/DecAmIND_POR.pdf Acesso em 27 mai. 2018.

32 OEA. Declaração Americana sobre os Direitos dos Povos Indígenas. Disponível em: https://www.oas.org/en/sare/documents/DecAmIND_POR.pdf Acesso em 27 mai. 2018. 
ALMEIDA, Bruno Rotta; SALLET, Bruna Hoisler. Realidades prisionais e vulnerabilização étnica: aspectos sobre a questão indígena no sistema penitenciário brasileiro. Revista Eletrônica Direito e Política, Programa de Pós-Graduação Stricto Sensu em Ciência Jurídica da UNIVALI, Itajaí, v.13, n.3, 30 quadrimestre de 2018. Disponível em: www.univali.br/direitoepolitica - ISSN 1980-7791

3. Os assuntos referentes a pessoas indígenas ou a seus direitos ou interesses na jurisdição de cada Estado serão conduzidos de maneira a proporcionar aos indígenas 0 direito de plena representação com dignidade e igualdade perante a lei. Por conseguinte, têm direito, sem discriminação, à igual proteção e benefício da lei, inclusive ao uso de intérpretes linguísticos e culturais.

4. Os Estados tomarão medidas eficazes, em conjunto com os povos indígenas, para assegurar a implementação deste Artigo ${ }^{33}$.

Diante do exposto, verifica-se que, no contexto internacional, os direitos indígenas foram progressivamente reformulados, reconhecendo-se a multiculturalidade e o respeito à singularidade desses grupos étnicos, de forma que, os Estados que ratificassem as normativas internacionais, incumbiam-se na tarefa de readequarem de seus ordenamentos jurídicos ao novo paradigma sobre a matéria.

Atualmente, no Brasil, não há qualquer menção ao trato individualizado a ser destinado aos povos indígenas em âmbito penal e prisional. O principal documento citado quando envolve a questão criminal é a Lei 6.001/1973, popularmente conhecida como Estatuto do Índio. O Estatuto foi promulgado durante o período da Ditadura Civil-Militar e tinha como finalidade a regulamentação da situação jurídica dos indígenas. O entendimento do referido documento era em consonância com o Código Civil de 1916 e indicava, em seu artigo 60, inciso IV, os silvícolas como relativamente incapazes, submetendo-os a um regime tutelar que "cessará à medida de sua adaptação"34.

Nesse sentido, transcreve-se o artigo 10 do Estatuto do Índio: "Esta Lei regula a situação jurídica dos índios ou silvícolas e das comunidades indígenas, com o propósito de preservar a sua cultura e integrá-los,

33 OEA. Declaração Americana sobre os Direitos dos Povos Indígenas. Disponível em: https://www.oas.org/en/sare/documents/DecAmIND_POR.pdf Acesso em 27 mai. 2018.

34 BRASIL. Lei no 6.001, de 19 de dezembro de 1973 (Estatuto do Índio). 1973. Disponível em: http://www.planalto.gov.br/ccivil_03/leis/L6001.htm Acesso em 27 mai. 2018. 
ALMEIDA, Bruno Rotta; SALLET, Bruna Hoisler. Realidades prisionais e vulnerabilização étnica: aspectos sobre a questão indígena no sistema penitenciário brasileiro. Revista Eletrônica Direito e Política, Programa de Pós-Graduação Stricto Sensu em Ciência Jurídica da UNIVALI, Itajaí, v.13, n.3, 30 quadrimestre de 2018. Disponível em: www.univali.br/direitoepolitica - ISSN 1980-7791

progressiva e harmonicamente, à comunhão nacional" 35 . No artigo 20 são elencados os deveres do Estado brasileiro para a proteção das comunidades indígenas e a preservação dos seus direitos, entre eles o de respeitar peculiaridades inerentes à sua condição e, durante o processo de integração do índio à comunhão nacional, respeitar seus valores culturais, tradições, usos e costumes; prestar assistência aos indígenas ainda não integrados à comunhão nacional; garantir aos índios a permanência voluntária no seu habitat, bem como a posse permanente das terras que habitam, reconhecendo-Ihes o direito ao usufruto exclusivo das utilidades e riquezas naturais.

O artigo 30 encarrega-se da definição de índio ou silvícola e de comunidade indígena ou grupo tribal. O primeiro é definido como indivíduo de "ascendência pré-colombiana que se identifica e é identificado como pertencente a um grupo étnico cujas características culturais o distinguem da sociedade nacional"36. O segundo é definido basicamente como um conjunto de famílias ou comunidades índias, que, vivendo em estado de completo isolamento ou em contatos permanentes com setores da comunhão nacional, não estão integrados a ela.

O artigo 40 traz a classificação do índio em I) isolado, II) em vias de integração e III) integrado. Os índios isolados são aqueles que "vivem em grupos desconhecidos ou de que se possuem poucos e vagos informes através de contatos eventuais com elementos da comunhão nacional"137, os índios em vias de integração são aqueles que conservam parte das condições de sua vida nativa, mas aceitam algumas práticas e modos de existência comuns aos demais setores da comunhão nacional, da qual vão

35 BRASIL. Lei no 6.001, de 19 de dezembro de 1973 (Estatuto do Índio). 1973. Disponível em: http://www.planalto.gov.br/ccivil_03/leis/L6001.htm Acesso em 27 mai. 2018.

36 BRASIL. Lei no $\mathbf{6 . 0 0 1}$, de 19 de dezembro de 1973 (Estatuto do Índio). 1973. Disponível em: http://www.planalto.gov.br/ccivil_03/leis/L6001.htm Acesso em 27 mai. 2018.

37 BRASIL. Lei no $\mathbf{6 . 0 0 1}$, de 19 de dezembro de 1973 (Estatuto do Índio). 1973. Disponível em: http://www.planalto.gov.br/ccivil_03/leis/L6001.htm Acesso em 27 mai. 2018. 
ALMEIDA, Bruno Rotta; SALLET, Bruna Hoisler. Realidades prisionais e vulnerabilização étnica: aspectos sobre a questão indígena no sistema penitenciário brasileiro. Revista Eletrônica Direito e Política, Programa de Pós-Graduação Stricto Sensu em Ciência Jurídica da UNIVALI, Itajaí, v.13, n.3, 30 quadrimestre de 2018. Disponível em: www.univali.br/direitoepolitica - ISSN 1980-7791

necessitando cada vez mais para o próprio sustento, e, por fim, os índios integrados são aqueles que, ainda que conservem usos, costumes e tradições característicos da sua cultura, são incorporados à comunhão nacional e reconhecidos o exercício dos direitos civis.

Por fim, o artigo 70 traz a delimitação de que somente os índios e as comunidades indígenas ainda não integrados à comunhão nacional ficam sujeitos ao regime tutelar estabelecido pelo Estatuto, devendo essa tutela ser oferecida pela União, que a exercerá através de órgão federal de assistência aos silvícolas, conforme parágrafo segundo do referido artigo ${ }^{38}$.

Acerca das normas penais, tem-se o título VI do Estatuto do Índio, sendo os artigos 56 e 57 destinados aos princípios e ao indígena condenado criminalmente, e os artigo 58 e 59 destinado aos crimes contra indígenas ou suas culturas.

O artigo 56 dispõe que deverá ser atenuada a pena do indígena condenado criminalmente, bem como que deverá o juiz, na sua aplicação, atender o grau de integração desse indivíduo. O parágrafo único do referido artigo faz referência ao cumprimento das penas de reclusão e detenção, devendo estas ser cumpridas, se possível, em regime especial de semiliberdade e no local de funcionamento do órgão federal de assistência aos índios mais próximo à habitação do indígena condenado.

O artigo 57 do Estatuto do índio dispõe que será tolerada a aplicação pelas comunidades indígenas de sanções penais ou disciplinares contra os seus membros, conforme suas instituições, desde que não revistam caráter cruel ou infamante, sendo absolutamente proibida a pena de morte.

Por fim, a Constituição Federal de 1988, diferentemente do Estatuto do Índio, uma vez que promulgada sob um contexto democrático, reconheceu, em seu artigo 231, a organização social, costumes, línguas, crenças e

38 BRASIL. Lei no 6.001, de 19 de dezembro de 1973 (Estatuto do Índio). 1973. Disponível em: http://www.planalto.gov.br/ccivil_03/leis/L6001.htm Acesso em 27 mai. 2018. 
ALMEIDA, Bruno Rotta; SALLET, Bruna Hoisler. Realidades prisionais e vulnerabilização étnica: aspectos sobre a questão indígena no sistema penitenciário brasileiro. Revista Eletrônica Direito e Política, Programa de Pós-Graduação Stricto Sensu em Ciência Jurídica da UNIVALI, Itajaí, v.13, n.3, 30 quadrimestre de 2018. Disponível em: www.univali.br/direitoepolitica - ISSN 1980-7791

tradições dos indígenas, bem como os direitos originários sobre as terras que tradicionalmente ocupam. Tal reconhecimento representa uma mudança paradigmática, tendo em vista que toda a legislação brasileira anterior foi pautada em uma noção integracionista e, a partir da Constituição Cidadã, a relação entre Estado e povos indígenas abandonou o princípio da integração e adotou o reconhecimento da condição multicultural brasileira.

Pautada nessa nova concepção multiculturalista, algumas políticas públicas de diversidade relacionadas à execução penal foram sendo implementadas em âmbito nacional. O documento do Departamento Penitenciário Nacional, intitulado "Modelo de Gestão para Política Prisional - 2016", possui um item que trata especificamente da "Política de inclusão e singularização do atendimento às pessoas em privação de liberdade com foco na garantia de direitos e no reconhecimento das diferenças e diversidades" 39 .

Entre umas das diretrizes apontadas pelo documento dirigente, destaca-se a diretriz no 23, a qual chama a atenção para a necessidade do respeito às diversidades geracionais, étnico/raciais, de gênero, de nacionalidade e de religião, devendo tal deferência ser pressuposto de todas as políticas e serviços realizados durante a execução penal.

A diretiva propõe, por exemplo, que as pessoas privadas de liberdade sejam chamadas pelo nome social, tenham alimentação e vestimentas de acordos com seus costumes, tenham possibilidade de realizar o seu culto religioso, assegurando a igual dignidade de todos os sujeitos presos, uma vez que teriam um plano de execução penal individualizado que atenderia às suas peculiaridades.

39 BRASIL. Ministério da Justiça. Departamento Penitenciário Nacional. Modelo de Gestão para a Política Criminal. 2016. Disponível em: http://www.justica.gov.br/modelo-degestao_documento-final.pdf Acesso em 27 mai. 2018. 
ALMEIDA, Bruno Rotta; SALLET, Bruna Hoisler. Realidades prisionais e vulnerabilização étnica: aspectos sobre a questão indígena no sistema penitenciário brasileiro. Revista Eletrônica Direito e Política, Programa de Pós-Graduação Stricto Sensu em Ciência Jurídica da UNIVALI, Itajaí, v.13, n.3, 30 quadrimestre de 2018. Disponível em: www.univali.br/direitoepolitica - ISSN 1980-7791

Nesse sentido, importante destacar que, para garantir factibilidade a tais políticas e serviços, primeiramente se faz necessária a superação da problemática que é o "processo de subnotificação e subidentificação de indígenas quando ingressam no sistema penal, promovendo sua invisibilização e negando acesso ao acompanhamento especializado"40.

Diante do exposto, verifica-se que existem normativas internacionais e políticas que direcionam para uma perspectiva que, embora tímida, é contra-hegemônica. Entretanto, a estrutura jurídico-penal brasileira está pautada por concepções consequentemente discriminatórias. A atual composição do sistema penal e penitenciário, conforme apontado acima, apresenta-se ainda mais hostil e degradante a pessoa indígena, cujas práticas e tradições próprias não consegue exercer, diferentemente do proposto pelas normativas nacionais e internacionais de respeito à própria diversidade.

\section{ENFRENTAMENTOS E NOVAS PERSPECTIVAS A PARTIR DAS REALIDADES PRISIONAIS}

O direito moderno, por meio do discurso da igualdade, silenciou indivíduos com diferentes etnias e culturas e, muitas vezes, promoveu o próprio apagamento dos mesmos. Tal situação pode ser bem verificada em países formados por uma população heterogênea, que apresentam minorias que carregam o peso da colonização e da superioridade de uma cultura dominante, como os povos indígenas.

Não diferentemente ocorre com a instituição da prisão, à medida que a população prisional, que é uma porção reduzida do corpo social, é constrangida a uma homogeneização específica, em que se exigem condutas também específica, sob o pretexto de adaptação do grupo a uma harmoniosa (sobre)vivência e bom funcionamento dos complexos

40 BRASIL. Ministério da Justiça. Departamento Penitenciário Nacional. Modelo de Gestão para a Política Criminal. 2016. Disponível em: http://www.justica.gov.br/modelo-degestao_documento-final.pdf Acesso em 27 mai. 2018. 
ALMEIDA, Bruno Rotta; SALLET, Bruna Hoisler. Realidades prisionais e vulnerabilização étnica: aspectos sobre a questão indígena no sistema penitenciário brasileiro. Revista Eletrônica Direito e Política, Programa de Pós-Graduação Stricto Sensu em Ciência Jurídica da UNIVALI, Itajaí, v.13, n.3, 30 quadrimestre de 2018. Disponível em: www.univali.br/direitoepolitica - ISSN 1980-7791

penitenciários ${ }^{41}$, desprezando-se, assim, as demandas dos diversos grupos populacionais presentes no microcosmo carcerário.

Nesse contexto de negação de direitos, os aspectos culturais são constantemente violados, conforme situações acima mencionadas, de modo que decorre a necessidade latente de repensar o próprio direito, bem como a justiça penal. O enfrentamento da questão deve buscar a potencialização da discussão sobre a configuração de realidades e de recepção de impactos de elementos políticos e sociais indissociáveis ao sistema punitivo, como seletividade, vulnerabilidade, sociabilidades, estigmatização e segregação ${ }^{42}$.

Boaventura de Souza Santos ${ }^{43}$ propõe a alternativa das Epistemologias do Sul. Trata-se de um conjunto de intervenções epistemológicas que denuncia a supressão de outros saberes, ao longo dos últimos séculos, pela norma epistemológica dominante. Dessa forma, uma epistemologia do Sul estaria assentada em três diretrizes, quais sejam, aprender que existe o Sul, aprender a ir para o Sul e aprender a partir do Sul e com o Sul. Para o autor, o Sul é concebido metaforicamente como um campo de desafios que procura reparar os danos e impactos historicamente causados pela relação colonial, sobrepondo-se em parte com o Sul geográfico, ou seja, aquele conjunto de países que foram submetidos ao colonialismo europeu, entre eles o Brasil.

A partir das Epistemologias do Sul, discorre-se, portanto, acerca do impacto do colonialismo na construção das epistemologias dominantes, afinal, ao impor a esses povos a catequização e valores eurocêntricos, suprimiu-se muitas formas de saber próprias dos povos indígenas, relegando seus saberes para um espaço de subalternidade.

41 NEUMAN, Elías. Victimologia y Control Social: las victimas del sistema penal. Buenos Aires: Universidad, 1994, p. 248.

42 CHIES, Luiz Antônio Bogo. Questão penitenciária: obstáculos epistemológicos e complexidade. Revista Paranaense de Desenvolvimento, Curitiba, v. 35, n. 126, jan./jun. 2014, p. 38.

43 SANTOS, Boaventura de Sousa; MENESES, Maria Paula. Epistemologias do Sul. Coimbra: Ed. Almedina, 2009, p. 7 ss. 
ALMEIDA, Bruno Rotta; SALLET, Bruna Hoisler. Realidades prisionais e vulnerabilização étnica: aspectos sobre a questão indígena no sistema penitenciário brasileiro. Revista Eletrônica Direito e Política, Programa de Pós-Graduação Stricto Sensu em Ciência Jurídica da UNIVALI, Itajaí, v.13, n.3, 30 quadrimestre de 2018. Disponível em: www.univali.br/direitoepolitica - ISSN 1980-7791

Além disso, indica-se também a possibilidade de pensar um 'outro' direito, que leve em consideração os saberes e costumes essenciais de povos subalternizados, tal como o pluralismo jurídico que, segundo Antônio Carlos Wolkmer ${ }^{44}$, designa a "existência de mais de uma realidade, de múltiplas formas de ação prática e da diversidade de campos sociais com particularidade própria, ou seja, envolve o conjunto de fenômenos autônomos e elementos heterogêneos que não se reduzem entre si".

Importante mencionar que, muitas vezes, o próprio multiculturalismo pode ser traduzido como a "coexistência de formas culturais ou de grupos caracterizados por culturas diferentes no seio de sociedades modernas" e do pluralismo jurídico, não se questionando s relações coloniais, restando apenas o reconhecimento e inclusão do 'outro'45.

Nesse sentido, aponta-se a crítica de Idon Moisés Chivi Vargas ${ }^{46}$ acerca do constitucionalismo moderno tradicional. Para ele, o constitucionalismo tradicional tem sido historicamente insuficiente para explicar as sociedades colonizadas, eis que não apresentou satisfatória clareza para elucidar a ruptura com as metrópoles europeias e a continuidade de relações caracteristicamente coloniais em suas respectivas sociedades ao longo dos séculos XIX, XX e parte do XXI.

Contribuição, portanto, do movimento de resistência da decolonialidade, o qual através de conceitos e noções próprias, identifica discursos que se dizem universais, mas na verdade são impregnados por colonialismo.

44 WOLKMER, Antônio Carlos. Pluralismo Jurídico. Fundamentos de uma nova cultura no Direito. 3. ed. rev. e atual. São Paulo: Editora Alfa Ômega, 2001, p. 171 ss.

45 SANTOS, Boaventura de Sousa. NUNES, João Arriscado. Introdução: para ampliar o cânone do reconhecimento, da diferença e da igualdade. In: SANTOS, Boaventura de Sousa (org.). Reconhecer para libertar: os caminhos do cosmopolitismo multicultural. Rio de Janeiro: Civilização Brasileira, 2003, p. 26.

46 VARGAS, Idón Moisés Chivi. Os caminhos da descolonização na América Latina: os povos indígenas e o igualitarismo jurisdicional na Bolívia. In: VERDUM, Ricardo (Org.). Povos indígenas: constituições e reformas políticas na América Latina. Brasília: Instituto de Estudos Socioeconômicos, 2009, p. 158. 
ALMEIDA, Bruno Rotta; SALLET, Bruna Hoisler. Realidades prisionais e vulnerabilização étnica: aspectos sobre a questão indígena no sistema penitenciário brasileiro. Revista Eletrônica Direito e Política, Programa de Pós-Graduação Stricto Sensu em Ciência Jurídica da UNIVALI, Itajaí, v.13, n.3, 30 quadrimestre de 2018. Disponível em: www.univali.br/direitoepolitica - ISSN 1980-7791

Denuncia, portanto, a lógica ocidental de realizar reformas legais, mas sem romper com práticas de dominação antigas.

Diante do exposto, notam-se diversas perspectivas que buscam de uma forma ou de outra evitar o silenciamento de grupos vulneráveis. A cultura de resistência ao cárcere, entrelaçada com a questão indígena, deve se atentar a tais perspectivas, adotando-as como estratégias de luta a possibilidade de um novo direito, vinculado à práxis jurídica e às proposições jurídico-histórico-sociais no Brasil.

\section{CONSIDERAÇÕES FINAIS}

A partir da presente investigação pode ser verificado que, assim como outros grupos minoritários, os indígenas também são vulnerabilizados no âmbito do sistema penal e prisional. Ainda há a imposição do ideário de indígena como aquele indivíduo totalmente desconexo da sociedade dominante, ignorando a atualidade vivenciada por esses povos.

A vulnerabilidade dos grupos sociais atingem a dignidade humana e a distribuição de políticas de respeito a direitos e assistências (saúde, jurídica, social, educacional, laboral etc.). A violência institucional sofrida pelos indígenas privados de liberdade também pode ser observada na ausência de representação adequada para acompanhar o processo penal, na inexistência de intérpretes para seu idioma, na carência de perícia antropológica, na participação insuficiente da FUNAI, e na deficiente e degradante estrutura das unidades penais (quase a totalidade das prisões do país não conta com celas ou alas específicas para o cumprimento de pena de pessoas indígenas).

Essas violências demonstram a gênese contraditória da própria prisão, a persistência de métodos e práticas, e a formação de um comportamento omisso do Estado perante seus cidadãos. Pode-se perceber, entretanto, um avanço, no contexto internacional, dos direitos indígenas, os quais foram reformulados, com o reconhecimento da multiculturalidade e o respeito à 
ALMEIDA, Bruno Rotta; SALLET, Bruna Hoisler. Realidades prisionais e vulnerabilização étnica: aspectos sobre a questão indígena no sistema penitenciário brasileiro. Revista Eletrônica Direito e Política, Programa de Pós-Graduação Stricto Sensu em Ciência Jurídica da UNIVALI, Itajaí, v.13, n.3, 30 quadrimestre de 2018. Disponível em: www.univali.br/direitoepolitica - ISSN 1980-7791

singularidade desses grupos étnicos, incumbindo-se aos Estados a tarefa de readequação dos ordenamentos jurídicos ao novo paradigma sobre a matéria.

O tímido avanço que se faz possível dentro de um interessante e progressivo sistema de normativas globais não é adotado pelo ordenamento jurídico brasileiro que, até a atualidade, possui um Estatuto do Índio totalmente em desacordo com os direitos humanos dos povos indígenas. Acerca do sistema penal e penitenciário, nenhuma menção aos povos tradicionais do Brasil é feita, o que demonstra o total descaso dos legisladores para com o assunto e com a realidade vivenciada. Além disso, o espaço prisional é um lugar de constantes violações de direitos fundamentais, atingindo a todos que estão custodiados, e ampliando-se, na medida das suas singularidades, aos grupos mais vulneráveis e vulnerabilizados.

Portanto, é impreterível repensar o direito, o qual, impregnado de colonialidade, ainda explora, violenta e silencia os indígenas durante séculos no país. Dentro de um contexto de negação de direitos, percebe-se uma compostura de violação da cultura. Para tanto, o enfrentamento deve procurar a potencialização da discussão sobre as realidades (seletividade, vulnerabilidade, sociabilidade, segregação etc.), para que seja possível compreender o impacto do colonialismo na distribuição da carga punitivo por meio da pena de prisão.

São diversas perspectivas existentes nos estudos pós-coloniais que podem colaborar com o rompimento do que está posto. Afinal, o poder punitivo do Estado brasileiro não acompanhou integralmente as novas orientações acerca das diversidades étnicas existentes, e ainda adota, de certa forma, um tratamento jurídico-penal de cunho etnocida. A perspectiva epistemológica tem de partir do Sul, e discorrer acerca do impacto do colonialismo na construção das epistemologias dominantes. No âmbito penal e prisional, essa cultura de resistência deve propor o surgimento ou 
ALMEIDA, Bruno Rotta; SALLET, Bruna Hoisler. Realidades prisionais e vulnerabilização étnica: aspectos sobre a questão indígena no sistema penitenciário brasileiro. Revista Eletrônica Direito e Política, Programa de Pós-Graduação Stricto Sensu em Ciência Jurídica da UNIVALI, Itajaí, v.13, n.3, 30 quadrimestre de 2018. Disponível em: www.univali.br/direitoepolitica - ISSN 1980-7791

ampliação de programas de enfrentamento da realidade carcerária por estratégias de luta que possam, até mesmo, reavaliar e potencializar os direitos fundamentais das pessoas privadas de liberdade.

\section{REFERÊNCIAS DAS FONTES CITADAS}

ABA - ASSOCIAÇÃO BRASILEIRA DE ANTROPOLOGIA; PGR PROCURADORIA GERAL DA REPÚBLICA. Criminalização e Situação Prisional de Índios no Brasil. Edital Projeto de Pesquisa ESMPU $\mathrm{n}^{\circ}$ 19/2006. Relatório Final. Brasília: ABA, 2008.

BAUMAN, Zygmunt. Globalização: as consequências humanas. Rio de Janeiro: Jorge Zahar, 1999.

BRASIL. Conselho Nacional de Justiça. Mutirão Carcerário do Estado de Mato Grosso do Sul - Relatório Geral. 2011. Disponível em: http://www.cnj.jus.br/images/programas/mutirao-

carcerario/relatorios/relatorio_final_mato_grosso_do_sul.pdf Acesso em 27 mai. 2018.

- Conselho Nacional de Justiça. Regras de Bangkok: Regras das Nações Unidas para o Tratamento de Mulheres Presas e Medidas Não Privativas de Liberdade para Mulheres Infratoras. 1. Ed - Brasília: Conselho Nacional de Justiça, 2016.

. Lei no 6.001, de 19 de dezembro de 1973 (Estatuto do Índio). $1973 . \quad$ Disponível em: http://www.planalto.gov.br/ccivil_03/leis/L6001.htm Acesso em 27 mai. 2018.

. Ministério da Justiça. Departamento Penitenciário Nacional. Levantamento Nacional de Informações Penitenciárias Infopen dezembro de 2014. Disponível em: http://www.justica.gov.br/ Acesso em: 25 fev. 2018.

. Ministério da Justiça. Departamento Penitenciário Nacional. Levantamento Nacional de Informações Penitenciárias Infopen junho de 2016. Disponível em: http://www.justica.gov.br/ Acesso em: 25 fev. 2018.

Ministério da Justiça. Departamento Penitenciário Nacional. Levantamento Nacional de Informações Penitenciárias Infopen junho de 2014. Disponível em: http://www.justica.gov.br/. Acesso em: 20 jan. 2018.

Ministério da Justiça. Departamento Penitenciário Nacional. Modelo de Gestão para a Política Criminal. 2016. Disponível em: 
ALMEIDA, Bruno Rotta; SALLET, Bruna Hoisler. Realidades prisionais e vulnerabilização étnica: aspectos sobre a questão indígena no sistema penitenciário brasileiro. Revista Eletrônica Direito e Política, Programa de Pós-Graduação Stricto Sensu em Ciência Jurídica da UNIVALI, Itajaí, v.13, n.3, 30 quadrimestre de 2018. Disponível em: www.univali.br/direitoepolitica - ISSN 1980-7791

http://www.justica.gov.br/modelo-de-gestao_documento-final.pdf Acesso em 27 mai. 2018.

. Ministério Da Justiça. Departamento Penitenciário. Postulados e Princípios Para a Política Nacional de Diversidades no Sistema Penal. 2016. Disponível em: http://justica.gov.br/seus-direitos/politicapenal/politicas-2/diversidades/publicacao-e-pesquisas Acesso em 27 mai. 2018.

Ministério da Saúde, Portal Saúde. Disponível em http://portalsaude.saude.gov.br/index.php/o-ministerio/principal/leia-maiso-ministerio/743-secretariasvs/vigilancia-de-a-a-z/tuberculose/I2tuberculose/11941-viajantes-tuberculose. Acesso em: 25 fev. 2018.

Mecanismo Nacional de Prevenção e Combate à Tortura. Relatório Anual 2016-2017. Disponível em: http://pfdc.pgr.mpf.mp.br/temas-deatuacao/tortura/relatorios-mnpc/relatorio-anual-2016-2017 Acesso em 27 mai. 2018.

CHIES, Luiz Antônio Bogo. Questão penitenciária: obstáculos epistemológicos e complexidade. Revista Paranaense de Desenvolvimento, Curitiba, v. 35, n. 126, jan./jun. 2014.

FERRAJOLI, Luigi. Filosofía del mal y garantismo. In: CUÉLLAR, Alejandro Forero; RIVERA BEIRAS, Iñaki; GORSKI, Hector C. Silveira. (ed.). Filosofía del mal y memoria. Anthropos Editorial; Observatori del Sistema Penal i els Drets Humans; Universitat de Barcelona: Barcelona, 2012.

GARLAND, David. A cultura do controle: crime e ordem social na sociedade contemporânea. Rio de Janeiro: Revan, 2008.

NEUMAN, Elías. El estado penal y la prisión-muerte. Buenos Aires: Editorial Universidad, 2001.

. Victimologia y Control Social: las victimas del sistema penal. Buenos Aires: Universidad, 1994.

OEA. Declaração Americana sobre os Direitos dos Povos Indígenas. Disponível em: https://www.oas.org/en/sare/documents/DecAmIND_POR.pdf Acesso em 27 mai. 2018

ONU. Declaração das Nações Unidas sobre os Direitos dos Povos Indígenas. $2008 . \quad$ Disponível em: http://www.un.org/esa/socdev/unpfii/documents/DRIPS_pt.pdf Acesso em 27 mai. 2018. 
ALMEIDA, Bruno Rotta; SALLET, Bruna Hoisler. Realidades prisionais e vulnerabilização étnica: aspectos sobre a questão indígena no sistema penitenciário brasileiro. Revista Eletrônica Direito e Política, Programa de Pós-Graduação Stricto Sensu em Ciência Jurídica da UNIVALI, Itajaí, v.13, n.3, 30 quadrimestre de 2018. Disponível em: www.univali.br/direitoepolitica - ISSN 1980-7791

http://www.ilo.org/brasilia/convencoes/WCMS_236247/lang--pt/index.htm Acesso em 27 mai 2018.

SANTOS, Boaventura de Sousa. NUNES, João Arriscado. Introdução: para ampliar o cânone do reconhecimento, da diferença e da igualdade. In: SANTOS, Boaventura de Sousa (org.). Reconhecer para libertar: os caminhos do cosmopolitismo multicultural. Rio de Janeiro: Civilização Brasileira, 2003.

SANTOS, Boaventura de Sousa. Para além do pensamento abissal: das linhas globais a uma ecologia de saberes. 2007. Disponível em: http://dx.doi.org/10.1590/S0101-33002007000300004 Acesso em 27 mai. 2018.

SANTOS, Boaventura de Sousa; MENESES, Maria Paula. Epistemologias do Sul. Coimbra: Ed. Almedina, 2009.

VARGAS, Idón Moisés Chivi. Os caminhos da descolonização na América Latina: os povos indígenas e o igualitarismo jurisdicional na Bolívia. In: WACQUANT, Loïc. Punir os pobres: a nova gestão da miséria nos Estados Unidos. Rio de Janeiro: Instituto Carioca de Criminologia, F. Bastos, 2001.

WOLKMER, Antônio Carlos. Pluralismo Jurídico. Fundamentos de uma nova cultura no Direito. 3. ed. rev. e atual. São Paulo: Editora Alfa Ômega, 2001.

Recebido em: 16/08/2018

Aprovado em: 16/10/2018 